fingers and toes, cleft of the soft palate, and cleft between the first and second toes. These were not present in our patient. Since our patient only had a small deletion of band $\mathrm{q} 24$, it is possible that the similar phenotype reported by Shabtai et al ${ }^{1}$ was due to the deletion which included band q23. The studies reported before did not use high resolution banding analysis. We regard it as important to use this technique in order to map accurately small deletions. It could be that patients considered to have overlapping deletions when standard techniques are applied have in fact different segments involved. This could account for the different phenotype found in our patient. With more widespread use of high resolution techniques, a better delineation of clinical syndromes seems possible. Our proband died at 16 months following an upper respiratory tract infection. The ages of death in the other cases were at 8 months, ${ }^{2} 20$ years, ${ }^{1}$ and at birth. ${ }^{3}$ The survival up to 20 years in the patient reported by Shabtai et al could be due to her mosaic state.

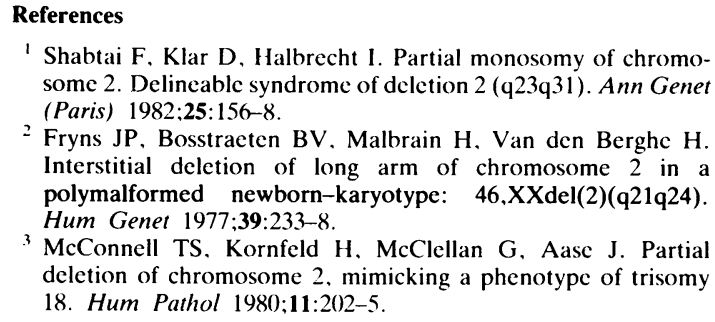

' Shabtai F. Klar D, Halbrecht I. Partial monosomy of chromosome 2. Delineable syndrome of deletion 2 (q23q31). Ann Genet (Paris) 1982:25:156-8.

2 Fryns JP, Bosstraeten BV, Malbrain H, Van den Berghe $H$. Interstitial deletion of long arm of chromosome 2 in a polymalformed newborn-karyotype: 46,XXdel(2)(q21q24). Hum Genet 1977;39:233-8.

${ }^{3}$ McConnell TS. Kornfeld H. McClellan G, Aase J. Partial deletion of chromosome 2, mimicking a phenotype of trisomy 18. Hum Pathol 1980;11:202-5.

Correspondence and requests for reprints to $\operatorname{Dr} \mathbf{J}$ Bernar, Division of Medical Genetics, Department of Pediatrics, UCLA Center for the Health Sciences, Los Angeles, California 90024, USA.

\title{
Hyperinsulinaemic hypoglycaemia in an infant with mosaic trisomy 13
}

\author{
VERNON S SMITH AND GEORGE P GIACOIA \\ Division of Neonatology, Eastern Oklahoma Perinatal Center; and Division of Neonatology, Department of \\ Pediatrics, Tulsa Medical College, Tulsa, Oklahoma, USA.
}

SUMMARY An infant with mosaic trisomy 13, who was small for gestational age, became severely hypoglycaemic. For the first 19 days of life, glucose requirements to maintain normoglycaemia were high (up to $21.7 \mathrm{mg} / \mathrm{kg} / \mathrm{min}$ ) and at the same time the infant had high plasma insulin levels and low glucose insulin ratios. Treatment with hydrocortisone and susphrine was of questionable benefit. Hyperinsulinism abated by the third week of life. This case illustrates early remission of hyperinsulinaemic hypoglycaemia and raises the possibility of an association with trisomy 13 .

Hypoglycaemia, although common in the premature or small for gestational age neonate, is rarely caused by hyperinsulinaemia in the neonatal period. Causes of neonatal hyperinsulinaemic hypoglycaemia are nesidioblastosis, adenomatoid dysplasia, islet cell adenoma, ectopic pancreatic tissue, and BeckwithWiedemann syndrome. ${ }^{1}$

Received for publication 3 August 1984 Accepted for publication 10 August 1984
This paper describes a mosaic trisomy 13 infant, small for gestational age, who developed hyperinsulinaemic hypoglycaemia. This association has not hitherto been reported.

\section{Case report}

The patient was a $2400 \mathrm{~g}, 37$ week female, small for gestational age, delivered to a 25 year old nondiabetic mother. The pregnancy was complicated by mild hypertension. The family history was negative for congenital malformations or mental handicaps. The infant was born by vaginal delivery and required endotracheal intubation and suction because of the presence of meconium beyond the vocal cords. The Apgar scores were 7 and 8 at one and five minutes, respectively. Because of meconium aspiration syndrome, the infant required mechanical ventilation for 12 hours followed by oxygen therapy for an additional three days.

The physical examination showed the following findings: malformed low set ears with small pinna, hypertelorism, elongated philtrum, micrognathia, elongated retroflexible thumbs held in a cortical position with clenched fists, and a two vessel cord. న 
Ultrasound of the abdomen revealed normal organ structure, position, and size. The infant had a cardiac dextroposition but echocardiography revealed normal cardiac structures. A patent ductus arteriosus responded to conservative medical management. The infant had congenital dislocated hips for which corrective surgery was necessary.

On admission, magnesium, calcium, and electrolytes were normal and the blood glucose was 50 $\mathrm{mg} / \mathrm{dl}$. At 12 hours of age, the infant became extremely jittery. A stat blood sugar was reported as unmeasurable. An injection of $10 \mathrm{cc}$ of $15 \%$ dextrose resulted in a blood glucose of $9 \mathrm{mg} / \mathrm{dl}$. The rate of dextrose infusion to maintain normoglycaemia was $14.8 \mathrm{mg} / \mathrm{kg} / \mathrm{min}$ at 36 hours and progressively rose to $21.7 \mathrm{mg} / \mathrm{kg} / \mathrm{min}$ on the sixth day. Blood insulin concentrations on the third and fourth days of life were 41 and $31 \mu \mathrm{U} / \mathrm{ml}$ (normal <12) with a concomittant blood glucose concentration of 32 and $26 \mathrm{mg} / \mathrm{dl}$ respectively (glucose/insulin ratios 0.8 ; normal $>3$ ).

Intravenous hydrocortisone $(15 \mathrm{mg} / \mathrm{kg} /$ day $)$ was started on the third day of life and tapered down from the tenth day onwards. It was discontinued on the 15th day of life. Susphrine $(0.01 \mathrm{ml} / \mathrm{kg} \mathrm{sc})$ was given twice on the seventh day to treat severe hypoglycaemia, but was discontinued because of systemic reaction to the drug.

The intravenous glucose requirements remained high $(20 \mathrm{mg} / \mathrm{kg} / \mathrm{min})$ up to the tenth day, but decreased the following week to 11 to $13 \mathrm{mg} / \mathrm{kg} / \mathrm{min}$. In the third week, frequent oral feedings were begun while the intravenous dextrose was slowly tapered off. The infant was totally on oral feedings at the age of 19 days.

Despite normoglycaemia, the infant remained jittery. An EEG on the twelfth day revealed paroxysmal epileptiform complexes. Phenobarbital therapy was initiated with success and has been discontinued during the first year of life. Both head sonogram and computerised tomography were normal. Chromosomal analysis of skin and blood revealed a mosaic trisomy 13. Developmental follow-up during the first year revealed a Bailey Developmental Quotient ranging between 99 and 110. The infant's blood glucose has remained normal and at 11 months of age, the fasting blood insulin concentration was $9.2 \mu \mathrm{U} / \mathrm{ml}$ and $<5 \mu \mathrm{U} / \mathrm{ml}$ two hours post-prandially.

\section{Discussion}

Secondary hypoglycaemia in the neonate has been known to complicate multiple congenital anomalies. Neonatal hypoglycaemia has been described in an infant with trisomy 18 and attributed to intrauterine malnutrition. ${ }^{2}$ Although our patient with mosaic trisomy 13 suffered from intrauterine growth retardation, her severe hypoglycaemia was secondary to hyperinsulinism. The diagnosis of hyperinsulinism in our case is confirmed by the demonstration of raised plasma insulin levels during documented hypoglycaemia and a high parenteral glucose infusion rate (over $15 \mathrm{mg} / \mathrm{kg} / \mathrm{min}$ ) to attain normoglycaemia.

Neonatal hypoglycaemia secondary to hyperinsulinism can be transient or persistent. Transient hyperinsulinism has been described in infants of diabetic mothers, erythroblastosis fetalis, Beckwith syndrome, and malposition of an umbilical artery catheter. ${ }^{3} \mathrm{~A}$ 'reactive' hypoglycaemia in response to glucose infusion can be demonstrated in most cases of transient hyperinsulinaemia.

Intractable hypoglycaemia results from persistently excessive secretion of insulin produced by a group of pathological pancreatic conditions which have been termed 'islet cell dysmaturation syndrome'. ${ }^{4}$ This syndrome includes the following islet pancreatic lesions: hypoplasia, hypertrophy, nesidioblastosis, nesidioblastoma, and islet cell adenoma. In addition, Beckwith syndrome can also be a cause of protracted hyperinsulinism.

The cause of the hyperinsulinism in our case remains unknown. None of the conditions associated with transient hyperinsulinaemia were present in our patient. To date, only two neonates with persistent hyperinsulinaemia had a spontaneous remission, at 3 weeks and 4 months of age respectively. ${ }^{56}$

Pancreatic heterotopic tissue has been described in association with trisomy $13 .^{7}$ Hypoglycaemia and hyperinsulinism can rarely complicate this condition. The short term hyperinsulinism in our patient militates against this possibility.

It has been suggested that persistent hyperinsulinaemic hypoglycaemia of infants is due to a failure in the normal functional maturation of the endocrine portion of the fetal pancreas. Infants with trisomy 13 have been found to have a delayed maturation in the synthesis of haemoglobin $\mathrm{A}_{2} .{ }^{8}$ It is tempting to speculate that the short lived insulin secretion dysfunction in our patient may represent another expression of delayed maturation in trisomy 13. This speculation, however, needs to be substantiated by concrete data.

In summary, we report a case of hyperinsulinaemic hypoglycaemia which illustrates the possibility of early spontaneous remission. The relationship in our case between trisomy 13 and hyperinsulinism, if any, remains undetermined. 


\section{References}

1 Cornblath M, Schwartz R. Disorders of carbohydrate metabolism in infancy. Philadelphia: Saunders, 1976:155-217.

${ }^{2}$ Orzalesi M, Renzulli F, Ferrante E, et al. Trisomy 18 and neonatal hypoglycaemia. Lancet 1967;ii:1211.

${ }^{3}$ Nagel JW, Sims JS, Aplin EC II, Westmark ER. Refractory hypoglycemia associated with a malpositioned umbilical artery catheter. Pediatrics 1979;64:315-7.

${ }^{4}$ Scully RE. Case records of the Massachusetts General Hospital: weekly clinico-pathological exercises. $N$ Engl $J$ Med 1978;229:241-8

5 Mayer T, Matlak ME, Lowry SF, et al. Protean manifestations of nconatal hyperinsulinism. Ann Surg 1981;194:140-5.
${ }^{6}$ Landau H, Perlman M, Meger S, et al. Persistent neonata hypoglycemia due to hyperinsulinism: medical aspects. Pediatrics 1982;70:440-6.

${ }^{7}$ Smith DW. Recognizable patterns of human malformations. Philadelphia: Saunders, 1982:18-9.

${ }^{8}$ Pinkerton PH, Cohen MM. Persistence of hemoglobin F in D/D translocation with trisomy 12-15 $\left(\mathrm{D}_{1}\right)$. JAMA 1967;200:647-9.

Correspondence and requests for reprints to $\mathrm{Dr}$ George P Giacoia, Division of Neonatology, Department of Pediatrics, Tulsa Medical College, 6161 South Yale, Tulsa, Oklahoma 74136, USA.

\section{Complex cardiac malformation in a case of trisomy 9}

\section{T WILLIAMS*, I ZARDAWI $\dagger$, R QUAIFE}

Departments of Child Health*, and Pathologyt, Leicester Royal Infirmary, Leicester; and the Cytogenetics Department $\ddagger$, Nottingham City Hospital, Nottingham.

SUMMARY A case of trisomy 9 showing a complex cardiac malformation is presented with a review of other published cases. A distinct trisomy 9 syndrome can be recognised with intrauterine growth retardation, short survival, consistent facial dysmorphism, congenital heart disease, and abnormalities of the skeletal, genital, and renal systems. There is no evidence for a maternal age effect.

Trisomy 9 has been described only rarely, most commonly in mosaic form. ${ }^{1}$ This report describes a baby who died shortly after birth, in whom chromosome studies were consistent with complete trisomy 9. The cardiac abnormalities were particularly severe and of a nature not previously documented in this disorder.

\section{Case report}

The patient, a female, was the product of the first pregnancy of healthy unrelated parents, the mother and father being 31 and 30 years of age respectively at the time of birth. A subsequent pregnancy resulted in a normal infant. There is no other relevant family history.

She was delivered at 35 weeks following spontaneous onset of labour and a pregnancy marked by intermittent vaginal bleeding between the tenth and twelfth weeks. Growth parameters at birth were

Received for publication 20 August 1984 Accepted for publication 29 August 1984 weight $1.65 \mathrm{~kg}$, length $41 \mathrm{~cm}$, and head circumference $31 \mathrm{~cm}$. The baby was cyanosed at birth with irregular respirations and died at the age of $1 \frac{1}{2}$ hours.

Craniofacial abnormalities included large fontanelles with a widely split sagittal suture, bilateral microphthalmia with left corneal clouding, a bulbous nasal tip, micrognathia with a central posterior cleft of the soft palate, and very low malformed ears (fig 1). Other findings included a loud harsh systolic murmur audible all over the praecordium, single

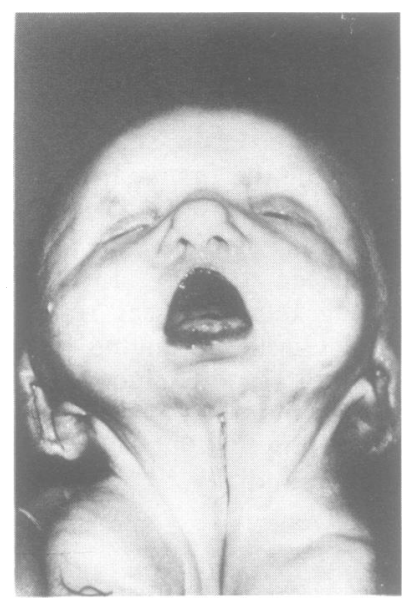

FIG 1 Post mortem view of the baby showing globular tip of the nose, posterior central cleft of the soft palate, and low set malformed ears. 